\title{
Enhanced Specificity and Drug Delivery in Tumors by CRGD - Anchoring Thermosensitive Liposomes
}

\author{
Bilyana M. Dicheva 1,4 • Timo L. M. ten Hagen ' Ann L. B. Seynhaeve • Mohamadreza Amin 1,3 • \\ Alexander M. M. Eggermont ${ }^{1,2} \cdot$ Gerben A. Koning ${ }^{1}$
}

Received: 18 March 2015 / Accepted: 24 June 2015 / Published online: 23 July 2015

(C) The Author(s) 2015

\begin{abstract}
Purpose To develop RGD-targeted thermosensitive liposomes with increased tumor retention, improving drug release efficiency upon mild hyperthermia (HT) in both tumor and angiogenic endothelial cells.
\end{abstract}

Methods Standard termosensitive liposomes (TSL) and TSL containing a cyclic Arg-Gly-Asp (cRGD) pentapeptide with the sequence Arg-Cys-D-Phe-Asp-Gly (RGDf[N-Met]C) were synthetized, loaded with Dox and characterized. Temperature- and time-dependent drug release profiles were assessed by fluorometry. Intracellular Dox delivery was studied by flow cytometry and confocal microscopy. Cytotoxic effect of TSL and RGD-TSL was studied on B16Bl6 melanoma, B16F10 melanoma and HUVEC. Intravital microscopy was performed on $\mathrm{B} 16 \mathrm{Bl} 6$ tumors implanted in dorsal-skin fold window-bearing mice. Pharmacokinetic and biodistribution of Dox-TSL and Dox-RGD-TSL were followed in $\mathrm{B} 16 \mathrm{Bl} 6$ tumor bearing mice upon normothermia or initial hyperthermia conditions.

Results DLS and cryo-TEM revealed particle homogeneity and size of around $85 \mathrm{~nm}$. Doxorubicin loading efficiency was $>95 \%$ as assessed by spectrofluorometry. Flow cytometry and confocal microscopy showed a specific uptake of RGD-TSL by melanoma and endothelial cells when compared to TSL and an increased doxorubicin delivery. High resolution intravital microscopy demonstrated specific accumulation of
RGD-TSL to the tumor vasculature. Moreover, application of hyperthermia resulted in massive drug release from RGDTSL. Biodistribution studies showed that initial hyperthermia increases Dox uptake in tumors from TSL and RGD-TSL. Conclusion RGD-TSL have potency to increase drug efficacy due to higher uptake by tumor and angiogenic endothelial cells in combination with heat-triggered drug release.

KEY WORDS Doxorubicin · drug delivery · hyperthermia . RGD - thermosensitive liposomes

$\begin{array}{ll}\text { ABBREVIATIONS } \\ { }^{\circ} \mathrm{C} & \text { Degree celsius } \\ \text { DMEM } & \text { Dulbecco modified eagle medium } \\ \text { Dox } & \text { Doxorubicin } \\ \text { DPPC } & \text { 1,2-dipalmitoyl-sn-glycero-3- } \\ & \text { phosphatidylcholine } \\ \text { DSPC } & \text { 1,2-distearoyl-sn-glycero-3- } \\ & \text { phosphatidylcholine } \\ \text { DSPE-PEG2000 } & 1,2 \text {-distearoyl-sn-glycero-3- } \\ & \text { phosphoethanolamine-N-PEG2000 } \\ \text { Em. } & \text { Emission } \\ \text { Ex. } & \text { Excitation } \\ \text { FCS } & \text { Fetal calf serum }\end{array}$

Electronic supplementary material The online version of this article (doi: | 0. I 007/s | | 095-0 I 5- | 746-7) contains supplementary material, which is available to authorized users.

Bilyana M. Dicheva

b.dicheva@erasmusmc.nl

Laboratory Experimental Surgical Oncology, Section Surgical Oncology Department of Surgery, Erasmus MC Cancer Center,

Rotterdam, The Netherlands
Institut Gustave Roussy, Villejuif, France

3 Department of Pharmaceutics, Mashhad University of Medical Sciences, Mashhad, Iran

4 Laboratory of Experimental Surgical Oncology, Department of Surgical Oncology, Erasmus MC Cancer Institute, PO Box 2040, 3000, CA Rotterdam, The Netherlands 


$\begin{array}{ll}\text { Fig. } & \text { Figure } \\ \text { GFP } & \text { Green fluorescence protein } \\ \text { H } & \text { Hours } \\ \text { HEPES } & \text { 4-(2-hydroxyethyl)-1- } \\ & \text { piperazineethanesulfonic acid } \\ \text { HT } & \text { Hyperthermia } \\ \text { i.v. } & \text { Intravenous } \\ \text { Min } & \text { Minutes } \\ \text { ml } & \text { Millilitre } \\ \text { NT } & \text { Normothermia } \\ \text { PDI } & \text { Polydisperisty index } \\ \text { S.C. } & \text { Subcutaneous } \\ \text { SD } & \text { Standard deviation } \\ \text { SEM } & \text { Standard error } \\ \text { TEM } & \text { Transmission electron microscopy } \\ \text { Tm } & \text { Melting temperature } \\ \text { TSL } & \text { Thermosensitive liposomes }\end{array}$

\section{INTRODUCTION}

Nanoparticles, such as liposomes have passed different stages of modifications in their design and nowadays are commonly used in cancer chemotherapy (1). Stealth liposomal nanoparticles of $100 \mathrm{~nm}$ are believed to accumulate passively in the tumor due to the leaky tumor vasculature and related enhanced permeability and retention effect $(2,3)$. Liposomes have contributed significantly to decrease toxic side effects caused by free drug administration (4-6). However, tumor accumulation of anticancer drugs using liposomes seemed far from optimal to guarantee improvement in therapeutic efficacy in clinical practice $(4,7)$. Low specificity of liposomes and their high intrinsic stability limit therapeutic outcome. Selectivity and efficacy can be achieved by decorating liposomes with targeting ligands, while an external trigger, e.g., heat, can control liposomal drug release. In this study we aimed at developing RGD-targeted thermosentitive liposomes, which combine active targeting of tumors together with a heat-triggered drug release function. These nanoparticles contain multiple RGD peptides on their surface to achieve tumor specificity and increased retention in tumors and a thermosensitive bilayer for heat-triggered drug release.

In order to efficiently target tumor cells, liposomes first need to extravasate from tumor vasculature and penetrate the tumor tissue. However, the extravasation process is usually heterogeneous and inefficient $(3,8)$. Targeting of tumor vasculature rather than tumor cells has become a promising approach in cancer therapy (9). In this case several tumor pathophysiological barriers do not play a role as endothelial cells are easily accessible to circulating chemotherapeutic drugs and deep penetration into tumor tissue is not necessary. Moreover, destruction of tumor vessels leads to indirect killing of tumor cells, which depend on their supply of oxygen and nutrients. Finally, endothelial cells are genetically stable and therefore less resistant to drug therapy (10). Besides vascular targeting, those small liposomes may extravasate through the leaky tumor vasculature and target tumor cells in addition (11).

Various vascular targets have been studied for antivascular therapy of which $\alpha \mathrm{v} \beta 3$ integrins have been used most often $(12,13)$. These integrins have been found to be overexpressed on tumor vasculature, but also on some metastatic melanoma cells $(14,15)$. The RGD (Arg-Gly-Asp) sequence is known to be a recognition motif for integrins such as $\alpha v \beta 3$ (16). Binding to either tumor or endothelial cells via specific receptors may lead to internalization of liposomal chemotherapy thereby bringing the drug closer to the nucleus. The combination of targeting properties of this nanoparticle with the heat-triggered release function might aid at releasing the drug locally in the tumor. Besides triggering drug release, hyperthermia (HT) is known to play a role in changing tumor environment by increasing tumor blood flow, oxygenation and vessel permeability (16-21).

An abundant amount of literature is available on thermosensitive or targeted liposomes (22-25). However, the combination of both strategies in one carrier is a promising approach. In the present study we describe the design, characterization and behavior of RGDtargeted thermosensitive liposomes containing the chemotherapeutic drug doxorubicin in vitro and in vivo. These liposomes were decorated with a novel and specific cyclic Arg-Gly-Asp (cRGD) pentapeptide containing the sequence Arg-Cys-D-Phe-Asp-Gly (RGDf[N-Met]G) (26). We tested the cytotoxic effect of those liposomes on melanoma cell lines and endothelial cells. Extensive live cell imaging was performed to study their intracellular fate in vitro. In vivo, their affinity for tumors, drug release kinetics and uptake were studied in dorsal skin fold window chamber models implanted with melanoma B16Bl6 tumors. Pharmacokinetics and biodistribution of Dox encapsulated in either TSL or RGD-TSL were investigated in mice implanted with $\mathrm{B} 16 \mathrm{Bl} 6$ tumors.

\section{MATERIALS AND METHODS}

\section{Chemicals}

The phospholipids 1,2-dipalmitoyl-sn-glycero-3phosphocholine (DPPC), 1,2-distearoyl-sn-glycero-3phosphocholine (DSPG), 1,2-distearoyl-sn-glycero-3phosphoethanolamine-N-PEG2000 (DSPE-PEG2000) were ordered from Lipoid (Ludwigshafen, Germany). 1,2dipalmitoyl-sn-glycero-3-phosphoethanolamine-N-(7-nitro-21,3 benzoxadiazol-4-yl) (NBD-PE) and 1,2-Disteroyl-snGlycero-3-Phosphoethanolamine-N-[Maleimide 
(Polyethylene Glycol)2000] (Ammonium Salt) were purchased from Avanti Polar Lipid Inc. Doxorubicin-HCl was from Pharmachemie (Haarlem, The Netherlands). The RGDf[NMet]Cys was provided by Peptron, South Korea. Sodium 3'-[(1-phenylaminocarbonyl)-3,4-tetrazolium]-bis(4-methoxy6-nitro)benzene sulfonic acid hydrate (XTT) was purchased from Sigma-Aldrich (Zwijndrecht, The Netherlands). LysoTracker Red DND-99 and Dioctadecyl tetramethylindotricarbocyanine perchlorate (DiD- $\left.\mathrm{C}_{18}(3)\right)$ were purchased from Invitrogen.

\section{Preparation of TSL}

TSL and RGD-TSL were composed of DPPC:DSPC:DSPEPEG2000 in a molar ratio 70:25:5. RGD peptide was coupled to $\mathrm{mPEG}$ in a molar ratio 1.1:1 (peptide:lipid) and coupling efficiency was confirmed by MALDI analysis. For MALDI analysis, all peptide samples were prepared as $0.001 \mathrm{M}$ in water. The matrix-assisted laser desorption/ionization (MALDI) 2,5-dihyfroxy benzoic acid was prepared as $10 \mathrm{mg} / \mathrm{mL}$ in water. Ten microliter of sample and $90 \mathrm{uL}$ of matrix solution were mixed and $0.5 \mathrm{uL}$ of this mixture was spotted on an anchor chip plate and allowed to dry at ambient temperatures. MALDI-TOF mass spectra were recorded on a Bruker Ultraflex III mass spectrometer, Bremen, Germany (27). Coupling of $>95 \%$ was used for further liposome preparation. Liposomes were prepared by lipid film hydration and extrusion method (16). The lipids were dissolved in chlorophorm and methanol (9:1 vol/vol). TSL used for confocal microscopy contained $0.3 \mathrm{~mol} \%$ of NBD-PE or $0.3 \mathrm{~mol} \% \mathrm{DiD}$ in the lipid bilayer. TSL used for intravital microscopy contained $0.3 \mathrm{~mol} \%$ of DiD. The solvent was subsequently evaporated in a rotary evaporator until homogeneous lipid film was formed. The lipid film was hydrated in $250 \mathrm{mM}\left(\mathrm{NH}_{4}\right)_{2} \mathrm{SO}_{4}$ solution with a $\mathrm{pH} 5,0$ at $60^{\circ} \mathrm{C}$ for $30 \mathrm{~min}$. The spontaneously formed liposomes were extruded subsequently 5 times through $100 \mathrm{~nm}, 5$ times through $80 \mathrm{~nm}$ and 5 times through $50 \mathrm{~nm}$ polycarbonate filter (thermo barrel extruder at $60^{\circ} \mathrm{C}$ ) and resulted in $<100 \mathrm{~nm}$ TSL. $\left(\mathrm{NH}_{4}\right)_{2} \mathrm{SO}_{4}$ outside of liposomes was removed from liposomal $\left(\mathrm{NH}_{4}\right)_{2} \mathrm{SO}_{4}$ by a PD-10 to PD 10 (GE Healthcare, Buckinghamshire, UK), eluted with HEPES buffer, pH $7.4(10 \mathrm{mM}$ HEPES, $135 \mathrm{mM} \mathrm{NaCl}$ ). Size and polydispersity index (PDI) were measured by dynamic light scattering using Zetasizer Nano ZS (Malvern Instruments, Worcestershire, UK). Lipid concentration was analysed by phosphate assay (27). After the phosphate concentration was determined, doxorubicin was loaded into the liposomes in 0,05:1 drug:lipid ratio (mol:mol) at $38^{\circ} \mathrm{C}$ for $1 \mathrm{~h}$. The liposomes were concentrated by ultracentrifugation for $2 \mathrm{~h}, 4^{\circ} \mathrm{C}, 106.000 \times \mathrm{g}$ (Ti50.2 rotor). The pellet was resuspended in HEPES buffer, $\mathrm{pH} 7.4$ and left overnight on slow rotation at $4^{\circ} \mathrm{C}$. Then the liposomes were passed through PD 10 column eluted with HEPES buffer,
pH 7.4 to remove free doxorubicin. Doxorubicin concentration was measured by spectrophotometer at Ex $480 \mathrm{~nm}$ and loading efficiency (\%) determined as [Dox/Lipid] after loading/[Dox/Lipid] before loading x100.

\section{TEM Cryo Imaging}

Samples were prepared by adding a $2 \mu$ l droplet of liposome suspension to a lacy carbon film and subsequently plungefreezing this sample into liquid ethane using a Vitrobot. An amorphous ('vitrified') ice film which contains the particles of interest was created. Cryo-TEM studies were performed using a FEI TECNAI F30ST (300 kV, using a cryo-holder, keeping the sample at $-174^{\circ} \mathrm{C}$ during the studies). Imaging was done in low-dose mode on a CCD camera (image size $1 \times 1 \mathrm{k}$ ).

\section{Stability at Physiological Conditions}

Stability of TSL and RGD-TSL was established by incubating $10 \mathrm{mM}$ [lipid]) in pre-heated FCS $(1: 149 \% / v)$ under stirring and Dox release was measured for $1 \mathrm{~h}$ at $37^{\circ} \mathrm{C}$. Samples without incubation were considered as a blank (Io). TSL were destroyed by adding 10\% Triton X-100 (150:1 v/v) and considered as a positive control $\left(\mathbf{I}_{\infty}\right.$ ). Fluorescence was measured by fluorometry at Ex. 479 nm / Em. 590 nm (Hitachi F-4500 Fluorescence Spectrophotometer). Dox release was determined as $\operatorname{Dox}(\%)=(\mathrm{It}-\mathrm{Io}) /\left(\mathrm{I}_{\infty}-\mathrm{Io}\right) \times 100$. Stability of liposomes was calculated as $100-\operatorname{Dox}(\%)$.

\section{In Vitro Dox Release}

Temperature-dependent Dox release kinetics from TSL and RGD-TSL were performed by fluorometry upon incubating the TSL samples (10 mM [lipid]) in pre-heated 90\% fetal calf serum (FCS) $(1: 9 \mathrm{v} / \mathrm{v})$ at temperatures ranging between 37 and $45^{\circ} \mathrm{C}$ for $5 \mathrm{~min}$ in a thermal-shaker (Eppendorf Thermomixer) at $300 \mathrm{rpm}$. Samples without incubation were considered as a blank (Io). After incubation, the samples were diluted in $10 \mathrm{mM}$ Tris/ $\mathrm{NaCl} 0.9 \%, \mathrm{pH} 8.0$ at 1:50 (v/v) and Dox fluorescence was measured by fluorimetry at Ex. $479 \mathrm{~nm}$ / Em. 590 nm. Maximum Dox fluorescence (positive control) $\left(\mathbf{I}_{\infty}\right)$ was achieved when incubating TSL suspension $(10 \mathrm{mM}$ [lipid]) in $2 \%$ Triton $\mathrm{X}-100$ in $\mathrm{H}_{2} \mathrm{O}$ for $30 \mathrm{~min}$ in a thermal shaker at $55^{\circ} \mathrm{C}$ and $1400 \mathrm{rpm}$. The Dox release (\%) was calculated as $\operatorname{Dox}(\%)=(\mathrm{It}-\mathrm{Io}) /\left(\mathrm{I}_{\infty}-\mathrm{Io}\right) \times 100$. In vitro timedependent Dox release from TSL and RGD-TSL was measured at $42^{\circ} \mathrm{C}$. TSL suspension (10 mM [lipid]) was mixed with pre-heated FCS $(1: 149 v / v)$ under stirring and Dox release was measured over time (at 1, 2, 3, 4, 5, 30, 60 min). TSL samples without heating were considered as a blank. TSL were destroyed by adding 10\% Triton X-100 (150:1 v/v) and considered as a positive control. The Dox release $(\%)$ was calculated as described above. 


\section{Cell Culture}

Tumor cell lines B16Bl6 (murine melanoma) and B16F10 (metastatic murine melanoma) were cultured in a Dulbecco's Modified Eagles' medium (Lonza, Belgium) containing 10\% FCS. Human umbilical vein endothelial cells (HUVECs) were isolated in-house and cultured in Human Endothelial SFM medium (Gibco, Invitrogen) enriched with 30\% FCS. Cells were passaged once a week using Trypsin (Sigma, Aldrich) and maintained at $37^{\circ} \mathrm{C}, 5 \% \mathrm{CO}_{2}$ in a humidified incubator. All experiments were performed at a confluence of $80-90 \%$.

\section{In Vitro Dox-TSL Toxicity}

B16Bl6, B16F10 and HUVEC cells were plated in 96 well plates at concentration 12,000 cells/well for B16Bl6 and B16F10 and 6000/well for HUVEC. The cells were allowed to attach for $24 \mathrm{~h}$ at $37^{\circ} \mathrm{C}$ and after that incubated with various concentrations of free Dox, Dox-TSL or RGD-Dox-TSL for $3 \mathrm{~h}$ at $37^{\circ} \mathrm{C}$. After $3 \mathrm{~h}$, liposomes were removed and cells washed three times with medium with FCS. Plates were placed at either normothermia $\left(\mathrm{NT} ; 37^{\circ} \mathrm{C}\right)$ or hyperthermia (HT; water bath at $42^{\circ} \mathrm{C}$ for $1 \mathrm{~h}$ ) and then left in the incubator at $37^{\circ} \mathrm{C}$ for additional $72 \mathrm{~h}$. Cell survival was determined by XTT assay. Electron coupling reagent $\mathcal{N}$-methyl dibenzopyrazine methylsulfate (1.25 mM in PBS; Sigma) $(100 \mu \mathrm{l})$ was mixed with $5 \mathrm{ml}$ of XTT solution $(1 \mathrm{mg} / \mathrm{ml}$ in RPMI 1640) and each well was incubated with $50 \mu$ l of this mixture for $1 \mathrm{~h}$ at $37^{\circ} \mathrm{C}$. Afterwards, XTT conversion was measured at $490 \mathrm{~nm}$ in a PerkinElmer Victor Wallac plate reader (Perkin Elmer, Groningen, The Netherlands).

\section{Flow Cytometry}

Binding of TSL or RGD-TSL to B16Bl6, B16F10 and HUVEC cells was assessed by flow cytometry (FACS) analysis. $1 \times 10^{5}$ cells in suspension were incubated for $3 \mathrm{~h}$ at $37^{\circ} \mathrm{C}$ with $400 \mathrm{nmol} / \mathrm{ml}$ TSL or RGD-TSL labelled with $0,3 \mathrm{~mol} \%$ NBD-PE. After incubation, cells were washed three times with medium with FCS to remove unbound liposomes. Liposomal NBD-PE fluorescence was determined at excitation and emission wavelengths of 470 and $530 \mathrm{~nm}$ by a BD FACScan (Becton Dickinson, San Jose, CA, USA). Dead cells were labelled with propidiumiodide (PI) (Sigma, Aldrich) and 10,000 gated events were acquired per sample and samples were prepared in triplicate. For Dox uptake FACS analysis, the same amount of cells was incubated with $100 \mu \mathrm{M}$ Dox for $3 \mathrm{~h}$ and subsequently washed $3 \times$ with medium with FCS. Cells in suspension were placed either at normothermia $\left(37^{\circ} \mathrm{C}\right)$ or hyperthermia $\left(42^{\circ} \mathrm{C}\right)$ for $1 \mathrm{~h}$. Dox fluorescence was determined at excitation and emission wavelengths of 488 and $585 \mathrm{~nm}$, respectively. As a dead cell marker, Sytox Green (Invitrogen) was used. Data was analysed with FlowJo software.
Experiments were performed three times with three different batches of liposomes.

\section{Live Cell Confocal Microscopy}

B16B16, B16F10 or HUVEC cells were seeded at the same concentrations as for fluorescent microscopy in cell culture chambers containing a cover glass insert coated with $0.1 \%$ gelatine. Cells were allowed to recover for $24 \mathrm{~h}$. After $24 \mathrm{~h}$, cells were incubated with $400 \mathrm{nmol} / \mathrm{ml} \mathrm{NBD-PE} \mathrm{labelled}$ TSL or RGD-TSL for $3 \mathrm{~h}$ at $37^{\circ} \mathrm{C}$ and for $30 \mathrm{~min}$ with lysotracker (LysoTracker® Red DND-99). After incubation, cells were washed three times with DMEM (B16Bl6 and B16F10) or HUVEG medium (HUVEC). Cells were analyzed on a Zeiss LSM 510 META confocal laser scanning microscope. NBD-PE fluorescence was detected by $513 \mathrm{~nm}$ argon laser and lysotracker was monitored by a $543 \mathrm{~nm}$ Helium Neon laser. For Dox release experiments, cells were incubated with NBD-PE or DiD labelled Dox-TSL or RGD-Dox-TSL for $3 \mathrm{~h}$ at $37^{\circ} \mathrm{C}$ and after that washed three times with medium with FCS. Dox release was followed in time for $1 \mathrm{~h}$ at $42^{\circ} \mathrm{C}$ (40 $\times$ objective lens, $2,5 \mu \mathrm{m}$ pinhole) and its fluorescence was detected by a $543 \mathrm{~nm}$ Helium -Neon laser. Images of $1024 \times 1024$ pixels were analyzed using Zeiss LSM image software (Zeiss, Germany).

\section{Animal Models}

B16Bl6 (murine melanoma) cells were cultured in DMEM medium with $10 \%$ FCS. Ten million tumor cells were injected subcutaneously in the flanks of C57Bl6 mice and bulk tumors of $10 \mathrm{~mm}$ in diameter were used for transplantation into C57Bl6, expressing an eNOS-tag-GFP fusion protein constitutively in their vascular endothelium. Tumor pieces were implanted in a dorsal skin flap window chamber for intravital imaging. Bulk mice were housed at $20-22^{\circ} \mathrm{C}$, humidity of 50 $60 \%$. Window chamber-bearing mice were used for experiments after 8-12 days of tumor implantation when tumor size reached 4-6 $\mathrm{mm}$ in diameter. These mice were housed in an incubator room with a humidity of $70 \%$ and temperature of $30-32^{\circ} \mathrm{C}$. All mice were fed a standard laboratory diet ad libitum (Hope Farms Woerden, the Netherlands). Mice weighing 20-25 g were used for experiments. All animal experiments were performed in compliance with protocols approved by the committee on Animal Research of the Erasmus MC, Rotterdam, The Netherlands.

\section{Intravital Microscopy for Dox Release upon Hyperthermia and Uptake by Tumor and Angiogenic Endothelial Cells}

Liposome binding to tumor vasculature and their clearance from circulation was analysed by intravital microscopy after 
injection of DiD-labelled TSL or RGD-TSL and followed up to 24 or $5 \mathrm{~h}$ respectively. In order to evaluate Dox release during hyperthermia and its uptake by tumor vascular endothelial cells and tumor cells, DiD-labelled Dox-TSL or RGDDox-TSL were injected i.v. through the penile or tail vein at a dose of $5 \mathrm{mg} / \mathrm{kgDox}$. Both formulations were allowed to circulate for $5 \mathrm{~h}$ at body temperature in order to be able to bind to vascular angiogenic endothelial cells or tumor cells and observed by confocal microscopy (Zeiss LSM 510 META). After $5 \mathrm{~h}$ of circulation, tumor was heated at $42^{\circ} \mathrm{C}$ for $1 \mathrm{~h}$ and Dox release and uptake was detected as above $(20 \times$ objective lens). Regions of interest were selected before, during and in the end of the hyperthermia treatment. Images of $1024 \times 1024$ pixels were analyzed using Zeiss LSM image software (Zeiss, Germany).

\section{In Vivo Dox Quantification}

The integrated density (IntDen) from the red channel (obtained after setting a threshold) representing released doxorubicin at $42^{\circ} \mathrm{C}$ into mice injected with either RGD-Dox-TSL or Dox-TSL was quantified from 13 positions from each group, which were obtained from three mice. The data are presented as an average of IntDen of all the positions of each mouse. The data was analyzed by Image $J$ software. When DiD quantified, 3-6 positions were used per mouse obtained from three mice from each group. The data are presented as an average of IntDen of all the positions of each mouse.

\section{Pharmacokinetic and Biodistribution of Dox-TSL and Dox-RGD-TSL}

Pharmacokinetic and biodistribution of Dox-TSL and DoxRGD-TSL was followed in B16Bl6 tumor bearing mice upon NT or initial HT conditions. At NT condition, mice were injected with $3 \mathrm{mg} / \mathrm{kg}$ Dox and blood sampling was performed at $0.1 ; 1 ; 2 ; 4 ; 6$ and $24 \mathrm{~h}$ and organs were collected $24 \mathrm{~h}$ after liposome injection. At HT condition, tumors were first preheated for $1 \mathrm{~h}$ at $41^{\circ} \mathrm{C}$ and then cooled down for $15 \mathrm{~min}$, in order to facilitate liposome extravasation. Then, liposomes were injected at $3 \mathrm{mg} / \mathrm{kg}$ Dox and blood samples were collected up to $24 \mathrm{~h}(0.1 ; 1 ; 2 ; 6 ; 24 \mathrm{~h})$, after which the organs were removed. The Dox concentration in the blood and organs was analyzed by HPLC and calculated as $\%$ injected dose $/ \mathrm{g}$ tissue $(\% \mathrm{ID} / \mathrm{g})$. Six mice were used per each group.

\section{Statistics}

In vivo drug release was analyzed by Mann-Whitney test and results with $p$-value $\leq 0.05$ were considered statistically significant.

\section{RESULTS}

\section{Liposome Characterization}

RGD-TSL and TSL consisted of the phospholipids DPPC, DSPC, DSPE-PEG2000 in a molar ratio (70:25:5). In the RGD-TSL formulation, RGD peptide was coupled to mPEG2000 and its coupling efficiency was analyzed by MALDI (Fig. 1), after which it was mixed with all the lipids in a molar ratio $(70: 25: 5)$. Both formulations were prepared by lipid film hydration and extrusion method (28). Dox was loaded into the liposomes after extrusion by $\left(\mathrm{NH}_{4}\right)_{2} \mathrm{SO}_{4}$ loading method (29). Liposomes were characterized by measuring size, polydisperity index (pdI), encapsulation efficiency and stability. All liposomes were $\sim 85 \mathrm{~nm}$ after extrusion and with a pdI $<0.1$. After Dox loading, liposomes retained their small size and a low pdI. Encapsulation efficiency of both formulations was $>95 \%$. Liposomes were comparably stable after $1 \mathrm{~h}$ of incubation at $37^{\circ} \mathrm{C}$ in $99 \%$ FCS. TSL contained $92 \% \pm 1.8$ of the entrapped Dox after $1 \mathrm{~h}$ at $37^{\circ} \mathrm{C}$ whereas RGD-TSL contained $85 \% \pm 2.3$ (data not shown).

\section{Temperature- and Time-Dependent Dox Release}

In order to test whether liposomes are thermosensitive, their temperature- and time-dependent drug release profiles were determined (Fig. 2a and b). According to the temperaturedependent release kinetics $(\mathrm{A})$, which was performed at varying temperatures $\left(37-45^{\circ} \mathrm{C}\right)$, both formulations were thermosensitive showing an increasing drug release with increasing temperature. The formulations were stable at physiological temperatures $\left(37-38^{\circ} \mathrm{C}\right)$ in $5 \mathrm{~min}$ and started to release their drug payload slightly at $39^{\circ} \mathrm{C}$. The maximum drug release from TSL in 5 min was observed at $42^{\circ} \mathrm{C}(\sim 85 \%)$, whereas for RGD-TSL it was at $43-44^{\circ} \mathrm{C}(\sim 80 \%)$, after which temperatures the drug release declined as seen before (21).

Time-dependent release profile at a constant temperature of $42^{\circ} \mathrm{C}$ for $1 \mathrm{~h}$ was similar for both formulations (Fig. 2b). RGD-TSL and TSL rapidly released Dox in the first minute and released $>90 \%$ of the encapsulated Dox in $1 \mathrm{~h}$.

Active loading of Dox into RGD-TSL and TSL by ammonium sulphate gradient method resulted in an abundant amount of intraliposomal Dox crystals, which were well visualized by TEM cryo imaging in both formulations (Fig. 2c).

\section{RGD-TSL Demonstrate Higher Uptake by Tumor and Endothelial Cells than Non-targeted TSL}

In order to test whether RGD coupling to liposomes increases liposomal uptake into tumor and endothelial cells, confocal microscopy and FACS analysis on melanoma B16Bl6 and B16F10 cells and HUVEC with NBD-PE labelled TSL or RGD-TSL was performed. Confocal microscopy on 

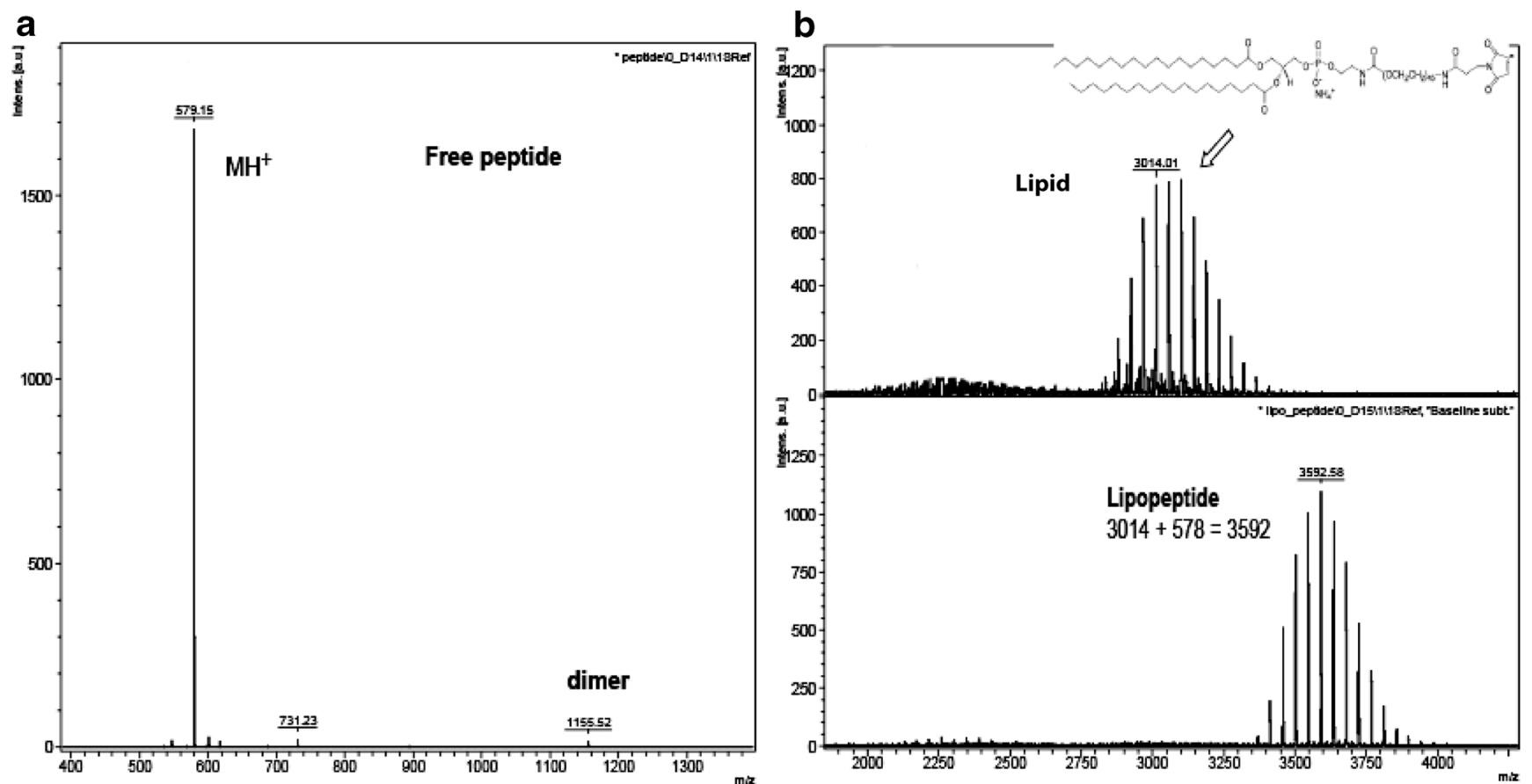

Fig. I MALDI-TOFF spectra of the free peptide RGD (a), the free lipid (b upper panel) and the coupled RGD to mPEG in lipopeptide (b lower panel).

B16B16, B16F10 and HUVEG demonstrated that RGD-TSL are more abundantly taken up by the tumor cells and HUVEC compared to TSL (Fig. 3a). The $3 \mathrm{~h}$ incubation

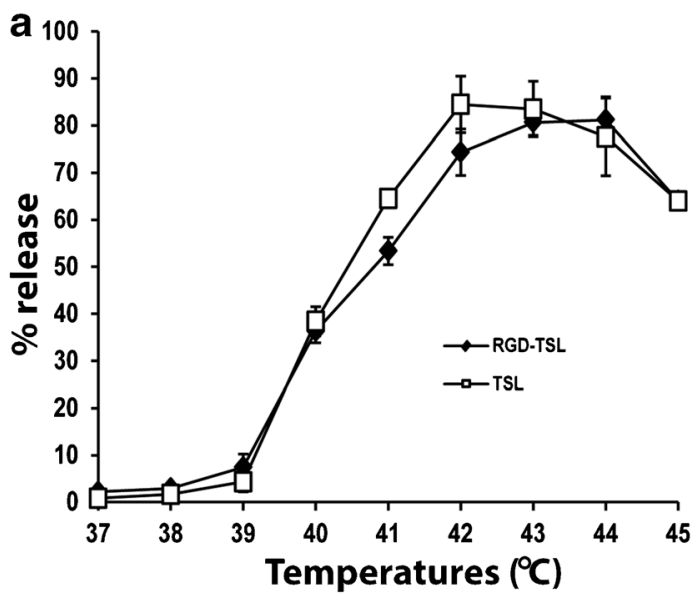

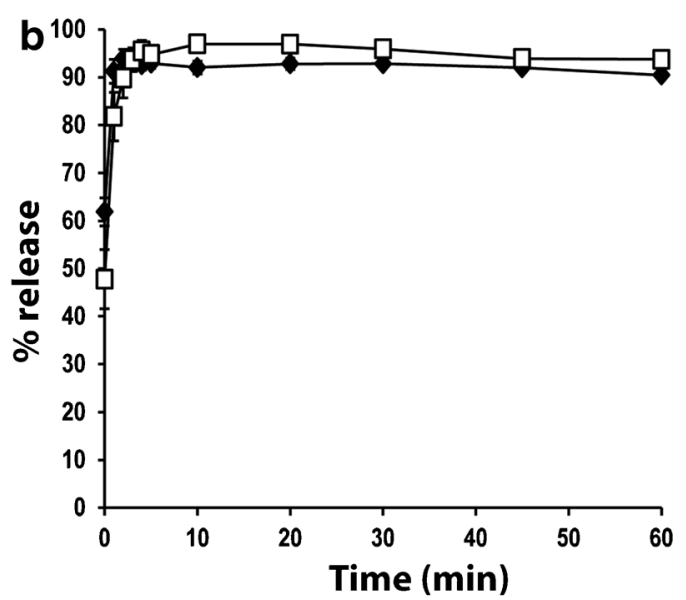

period at $37^{\circ} \mathrm{C}$ followed by a washing step for removal of unbound liposomes revealed that the RGD modification of TSL led to a preferential binding and uptake by all the cell
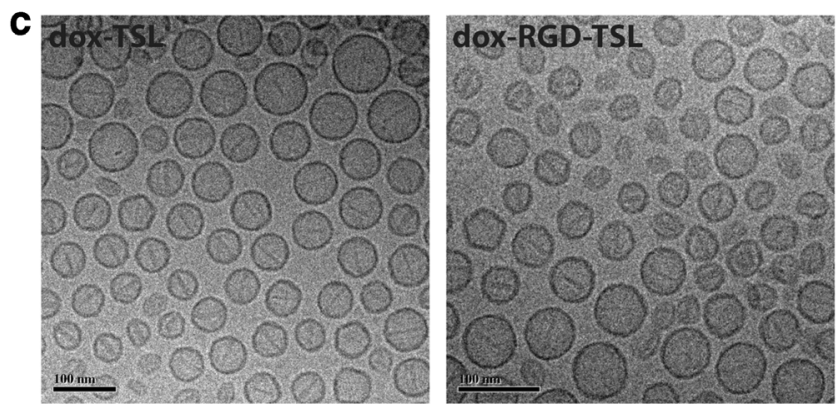

Fig. 2 Temperature- (a) and time- (b) dependent Dox release kinetics from RGD-TSL and TSL. Temperature-dependent drug release profile was performed in temperatures between 37 and $45^{\circ} \mathrm{C}$ for 5 min in $90 \%$ FCS. Time-dependent release was carried for $1 \mathrm{~h}$ at $42^{\circ} \mathrm{C}$ in $99,7 \%$ FCS. Mean of three independent experiments with three different batches of liposomes. TEM-cryo imaging (c) of Dox-TSL and Dox-RGD-TSL. Bar, $100 \mathrm{~nm}$. 

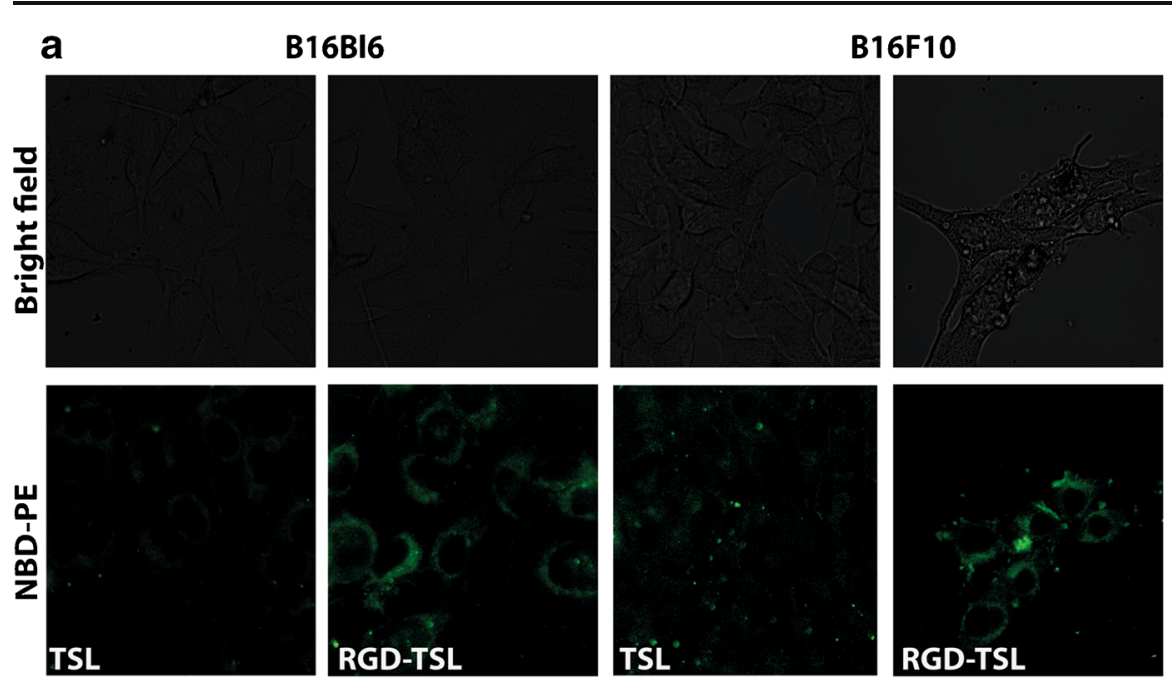

C

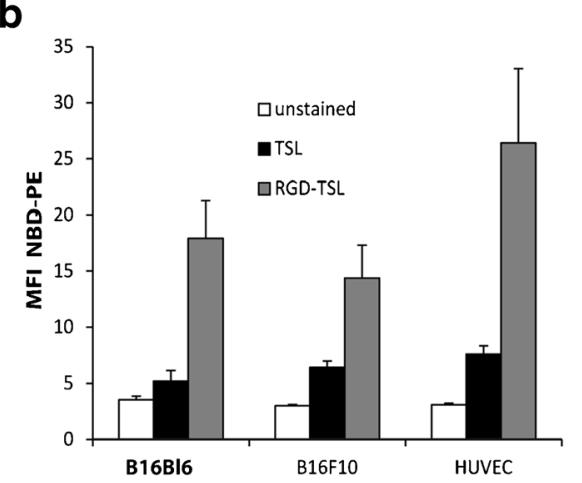

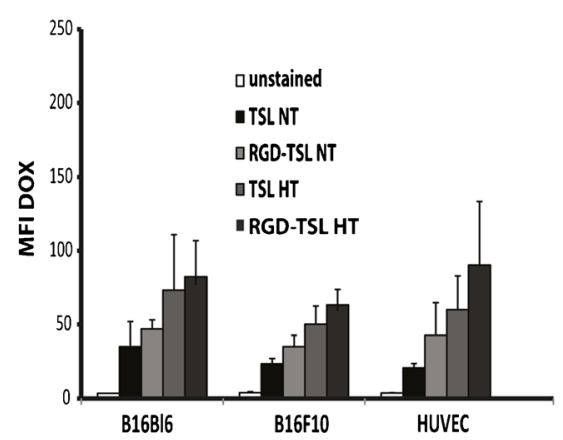

HUVEC
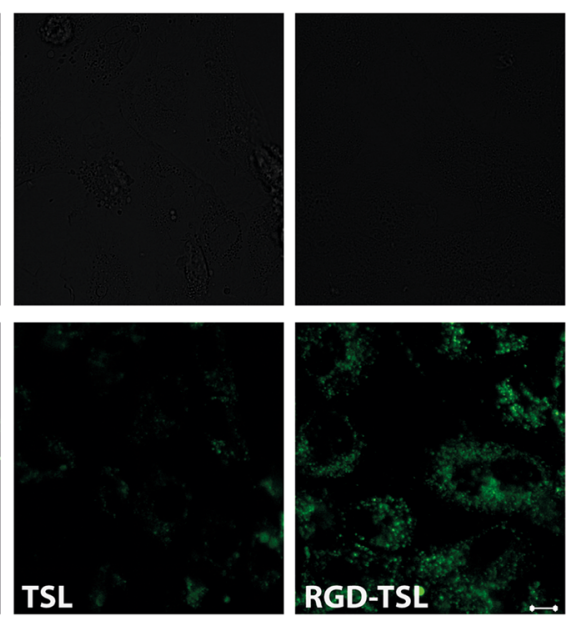

d

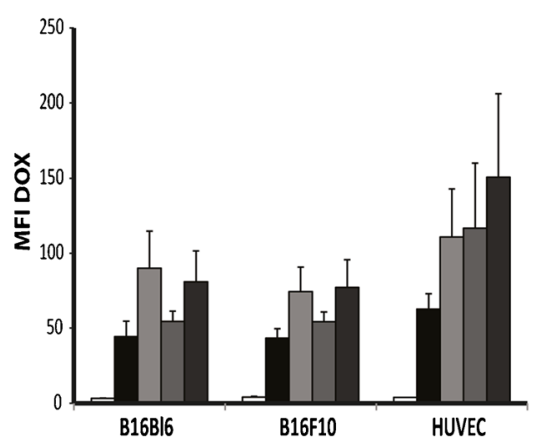

Fig. 3 Confocal live-cell imaging for preferential uptake of RGD-TSL compared to TSL into BI6BI6, BI 6FI 0 and HUVEC cells after 3 h of incubation at $37^{\circ} \mathrm{C}$ (a). Unbound liposomes were removed by washing. Scale bar applies for all images, $10 \mu \mathrm{m}$. Intracellular NBD-PE fluorescent intensity represented as mean fluorescent intensity (MFI) in melanoma B $6 \mathrm{Bl} 6, \mathrm{BI} 6 \mathrm{FI} 0$ cells and HUVEC (b) treated with either TSL or RGD-TSL for $3 \mathrm{~h}$ at $37^{\circ} \mathrm{C}$. Unbound liposomes were removed by washing. As unstained cells are used cells which were not incubated with liposomes. c and $\mathbf{d}$. Intracellular Dox uptake represented as MFI in melanoma BI6BI6, BI6FIO cells and HUVEC after I h (c) or $3 \mathrm{~h}(\mathbf{d})$ of incubation at $37^{\circ} \mathrm{C}$, washing of unbound liposomes, followed by I h of $\mathrm{HT}$ at $42^{\circ} \mathrm{C}$.

lines. This was confirmed also by FACS analysis (Fig. 3b). In order to measure Dox delivery, FACS analysis was performed in B16Bl6, B16F10 and HUVEC after $1 \mathrm{~h}(\mathrm{C})$ or $3 \mathrm{~h}(\mathrm{D})$ of incubation with Dox-TSL or Dox-RGD-TSL followed by $1 \mathrm{~h}$ of $\mathrm{HT}$ at $42^{\circ} \mathrm{C}$. The amount of Dox delivered from RGD-TSL at NT was higher than TSL in all cell lines and this amount further increased after $3 \mathrm{~h}$ of incubation. When HT was applied to the cells after $1 \mathrm{~h}$ of incubation at $37^{\circ} \mathrm{C}$, there was an increase in Dox release and uptake in all cell lines. HT trigger did not further increase the delivered Dox to B16Bl6 and B16F10 cells after $3 \mathrm{~h}$ of incubation. Only in HUVEGs there was an increased delivery of Dox upon HT after $3 \mathrm{~h}$ of incubation.

\section{Uptake of RGD-TSL in Lysosomes and Intracellular, HT-Triggered Dox Release from RGD-TSL in Tumor and Endothelial Cells}

The intracellular localization of liposomes was studied by live cell imaging in B16Bl6, B16F10 and HUVEC (Fig. 4a). Cells were incubated with NBD-PE labelled (green) RGD-TSL and lysotracker (red, to stain lysosomes) for $3 \mathrm{~h}$ at $37^{\circ} \mathrm{C}$, after which the unbound liposomes were removed by washing. $\mathrm{B} 16 \mathrm{Bl} 6$ and B16F10 were able to localize the RGD-TSL in the cytoplasm after $3 \mathrm{~h}$ of incubation and those liposomes were colocalized with the red lysotracker, seen as yellow fluorescence signal (white arrows). Still, there were some RGDTSL (green fluorescence spots), which were not concentrated in the acidic compartments (blue arrows). By contrast, in HUVEC sequestering of RGD-TSL in the lysosomes occurred at a slower pace. After $3 \mathrm{~h}$ of incubation at $37^{\circ} \mathrm{C}$, liposomes and lysotracker were observed as green and red separated fluorescence signals, showing no entrapment of the liposomes in the lysosomes. However, when cells were followed for a prolonged period, colocalization (in yellow) started to be visible. After $7 \mathrm{~h}$ of incubation, there was an abundant amount of RGD-TSL localized in the lysosomes but also some non-entrapped liposomes in lysosomes could be observed.

To prove that Dox-RGD-TSL deliver the encapsulated drug intracellular, live cell imaging on B16B16, B16F10 and 


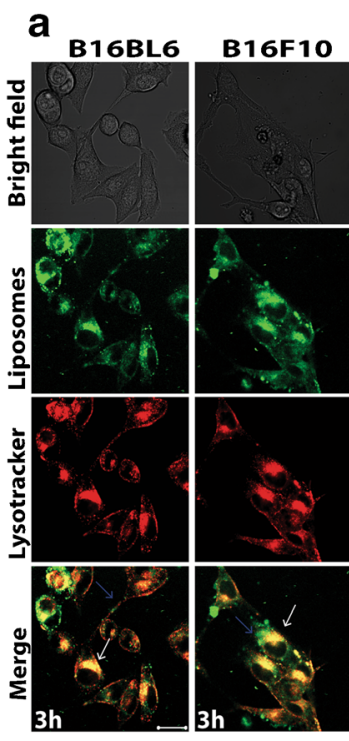

b
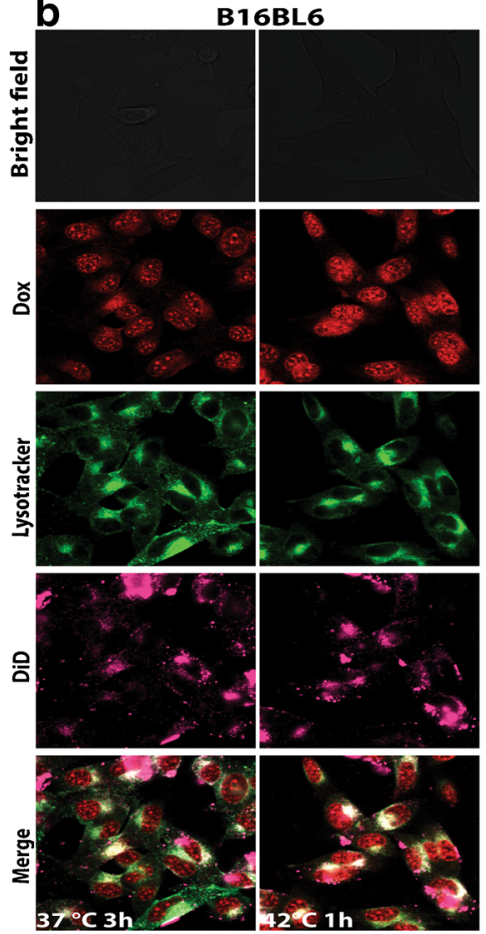

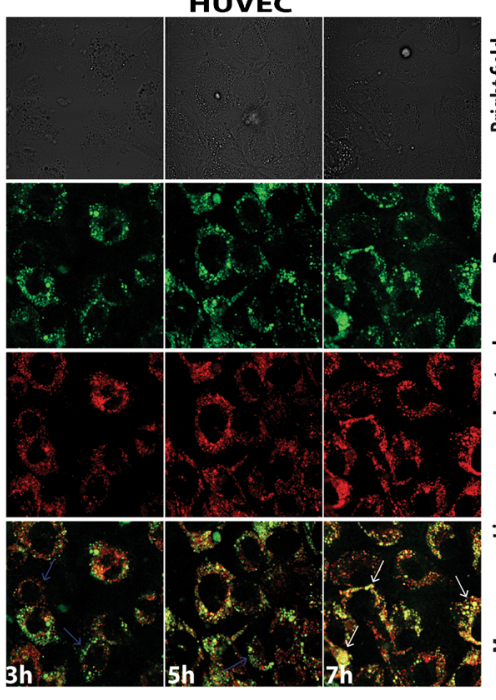

B16F10

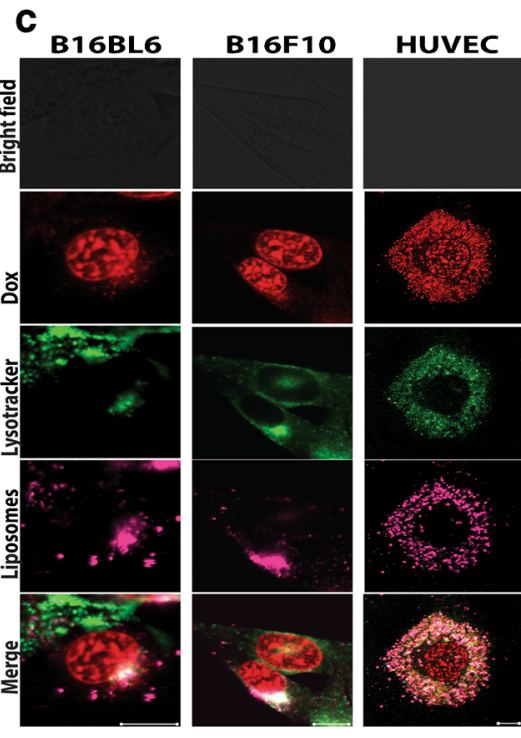

HUVEC
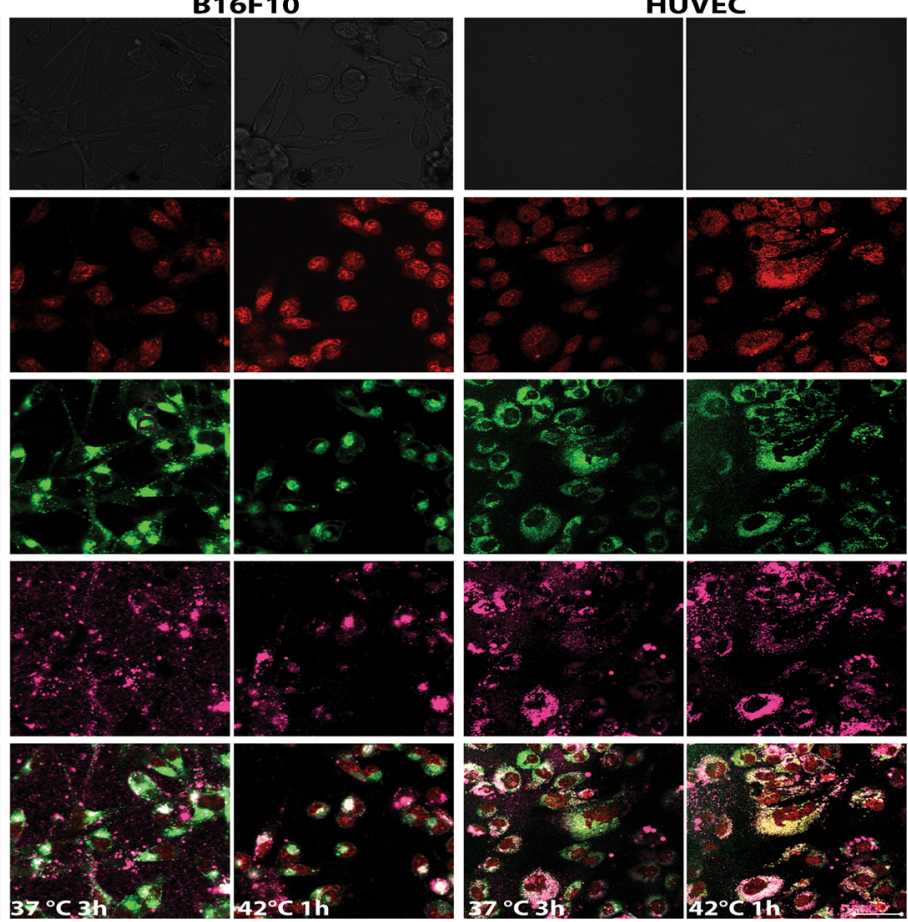

Fig. 4 (a). Confocal microscopy on melanoma BI6Bl6 and BI6FIO cells and HUVEC incubated with NBD-PE (green) labelled RGD-TSL for $3 \mathrm{~h}$ at $37^{\circ} \mathrm{C}$ and lysotracker (red). Unbound liposomes were removed by washing $3 \times$ with medium without FCS. After washing, B $6 \mathrm{Bl} 6$ and BI6FI0 were immediately imaged at $37^{\circ} \mathrm{C}$, whereas HUVEC were followed up to $7 \mathrm{~h}$. Internalized liposomes in the cytosol can be observed in all the cell lines (white arrows). Non-internalized in the lysosomes liposomes were also visible (blue arrows). B $16 \mathrm{Bl} 6$ and B 16 internalized liposomes immediately in the lysosomes after the $3 \mathrm{~h}$ of incubation period (yellow colocalization of green liposomes and red lysotracker), whereas this process happened in HUVEC after $7 \mathrm{~h}$. Images were taken by confocal microscope (40X, 2,5 $\mu \mathrm{m}$ pinhole, $2 \times$ zoom). Scale bar applies for all images, $20 \mu \mathrm{m}$. (b). Doxorubicin release (red) from DiD-labelled RGD-TSL (purple) in BI 6BI6, B I6F I 0 and HUVEC upon HT trigger. Cells were incubated with $50 \mu \mathrm{M}$ Dox for $3 \mathrm{~h}$ at $37^{\circ} \mathrm{C}$, after which cells were washed $3 \times$ with medium without FCS. Images were taken right after this incubation at $37^{\circ} \mathrm{C}$. Then, $\mathrm{HT}$ at $42^{\circ} \mathrm{C}$ for I h was applied and images in the end of the $\mathrm{HT}$ treatment were recorded. Images were taken by confocal microscope. Scale bar applies for all images, $50 \mu \mathrm{m}$. (c). Colocalization of RGD-TSL (purple) with lysotracker (green) and Dox release (red) in the lysosomes. Scale bar applies for all images, $10 \mu \mathrm{m}$.

HUVEC was performed using DiD labelled Dox-RGD-TSL and green lysotracker (Fig. 4b). Removing the unbound liposomes $3 \mathrm{~h}$ after incubation at $37^{\circ} \mathrm{C}$ resulted in some doxorubicin release inside of all cell lines, most probably due to processing of liposomes by the cells in this time frame. The released Dox localized mainly in the cell nuclei but could also be observed in the cytoplasm. The application of HT for $1 \mathrm{~h}$ triggered additional Dox release, seen as increased red 
fluorescence signal intracellularly. In B16Bl6 and B16F10, the Dox delivery upon HT treatment was predominantly nuclear, whereas in HUVEC it was cytoplasmic (Fig. 4b and c). In accordance with Fig. 4a, DiD-labeled RGD-TSL (purple) also localized in lysosomes (green) to some extent. Non-colocalized liposomes with lysosomes could also be observed. Interestingly, the released cytoplasmic Dox upon HT colocalized with the green lysotracker, which indicates Dox release from RGDTSL also occurs in acidic compartments in the cytosol (Fig. 4b and c).

\section{Cytotoxicity of Dox Encapsulated in TSL and RGD-TSL upon NT and HT}

Incubation of B16Bl6,B16F10 and HUVEG cells for $3 \mathrm{~h}$ with Dox-TSL or Dox-RGD-TSL showed no differences in cell toxicity determined $72 \mathrm{~h}$ later as seen in Fig. 5 and Table 1. Application of $\mathrm{HT}$ for $1 \mathrm{~h}$ at $42^{\circ} \mathrm{C}$ after $3 \mathrm{~h}$ of liposomes incubation could not further improve cytotoxicity impact $72 \mathrm{~h}$ later in B16F10 and HUVEC but only to some extent in B16Bl6 cells. Free Dox demonstrated the highest cytotoxicity on all the cell lines because it is rapidly taken up by the cells in its free form.

\section{Binding to- and Extravasation from Tumor Vasculature of TSL and RGD-TSL}

In order to proof that RGD-TSL target angiogenic endothelial cells in vivo, intravital microscopy in B16Bl6 window chamber bearing mice was performed. To visualize circulating liposomes in the blood stream, liposomes were labelled with $\mathrm{DiD}$ (purple). In these mice tumor vasculature is visualized by the constitutive expression of a GFP-eNOS-tag fusion protein in endothelial cells (Fig. 6). Twenty minutes after injection of RGD-TSL, next to circulating liposomes in the lumen of the blood vessels, bound RGD-TSL could be observed (Fig. 6a yellow arrows). These liposomes can be visualized as patchy fluorescent spots on the vessel walls. Besides bound liposomes to the angiogenic endothelial cells, extravasated liposomes from tumor vasculature are visible already $20 \mathrm{~min}$ after injection (white arrows). They are visible as diffuse purple fluorescence outside of the green blood vessels. Binding continued in time and was pronounced $24 \mathrm{~h}$ after injection. In contrast, using DiD-labeled TSL, no binding to tumor vasculature was detected after $5 \mathrm{~h}$ of circulation. In the last time point ( $24 \mathrm{~h}$ ), only extravasated TSL were visible (Fig. 6a, right panel).

Liposome clearance from circulation during the $5 \mathrm{~h}$ targeting phase and Dox triggered release upon HT was further evaluated by intravital microscopy in $\mathrm{B} 16 \mathrm{Bl} 16$ window chamber bearing mice (Fig. 6b). Liposome clearance was observed already $2 \mathrm{~h}$ after injection by decrease in DiD fluorescence signal from both RGD-TSL and TSL. Clearance of liposomes continued in time up to $5 \mathrm{~h}$ (Fig. $6 \mathrm{~b}$ and c). However,
RGD-TSL bound to tumor vasculature were visible already 5 min after injection, whereas this was not observed for TSL even after $5 \mathrm{~h}$ of circulation, which is in accordance with Fig. $6 \mathrm{a}$. $\mathrm{HT}$ trigger at $42^{\circ} \mathrm{C}$ for $1 \mathrm{~h}$ did not seem to cause any additional clearance neither of RGD-TSL or TSL. Upon HT, TSL could be observed extravasated from the tumor vasculature (white arrows), a process which is known to be heterogeneous within the tumor. This is in accordance with the quantification of the images, showing an increase of the TSL signal upon HT, which is most probably due to extravasation. However, there was no increase of the RGD-TSL levels upon HT (Fig. 6c).

\section{In Vivo Dox Release upon HTand Dox Uptake by Tumor and Endothelial Cells}

In order to understand whether RGD-TSL release Dox in viwo upon HT treatment and to follow Dox distribution in the tumor, intravital microscopy was performed. Circulation of TSL and RGD-TSL for $5 \mathrm{~h}$ in the blood stream did not cause any premature release of Dox (data not shown). However, when $\mathrm{HT}$ at $42^{\circ} \mathrm{C}$ was applied, immediate Dox release (red) was observed from TSL (Fig. 7a) and RGD-TSL (Fig 7b). Dox from both formulations was released first intravascularly from the circulating DiD-labelled liposomes (purple), after which it was gradually taken up by endothelial cells and tumor cells surrounding the blood vessels (Fig. 7d and supporting information, video 1). The Dox uptake in the both treatment groups increased in time and was maximal after $1 \mathrm{~h}$ of HT, when also the lumen of the blood vessels was cleared from Dox. Quantification of the images showed that the amount of delivered Dox to the tumor from RGD-TSL was 1.7 fold higher than from TSL (Fig. 7c). However, this difference was not statistically significant $(p$-value $=0.8$ ).

To follow up Dox clearance from circulation, its distribution in healthy organs and tumors and to be able to quantify Dox concentrations in tumors and organs, the pharmacokinetic and biodistribution profiles of Dox in TSL or RGD-TSL were studied (Fig. 8) under NT or initail HT conditions. At NT condition (Fig. 8a and c), Dox from both formulations seemed to clear from circulation quite fast in the first $1 \mathrm{~h}$, as it was faster for RGD-TSL than for TSL $(27 \% \mathrm{v} / \mathrm{s} 52 \%$ remaining Dox respectively). After $2 \mathrm{~h}$ of liposome circulation, the trend was the same showing lower remaining Dox from RGD-TSL than from TSL (10\% v/s 20\% respectively). At later time points $(4,6,24 \mathrm{~h})$ there was barely any Dox present in circulation from TSL and RGD-TSL. The application of initial HT (Fig. 8b) seemed to increase the presence of Dox from RGD-TSL in circulation at $1 \mathrm{~h}$ time point, after which its clearance was the same as at NT conditions. Besides, upon initial HT conditions, clearance of Dox from TSL and RGDTSL was similar. Considering the biodistribution of Dox (Fig. 8c and d), at both NT and HT conditions, there was a significant uptake of Dox from both formulations in the spleen 
Fig. 5 Cytotoxicity of Dox-TSL and Dox-RGD-TSL either at 37 or $42^{\circ} \mathrm{C}$ in $\mathrm{BI} 6 \mathrm{Bl} 6(\mathbf{a}), \mathrm{BI} 6 \mathrm{FIO}(\mathbf{b})$ and HUVEC (c) determined $72 \mathrm{~h}$ after liposome incubation.
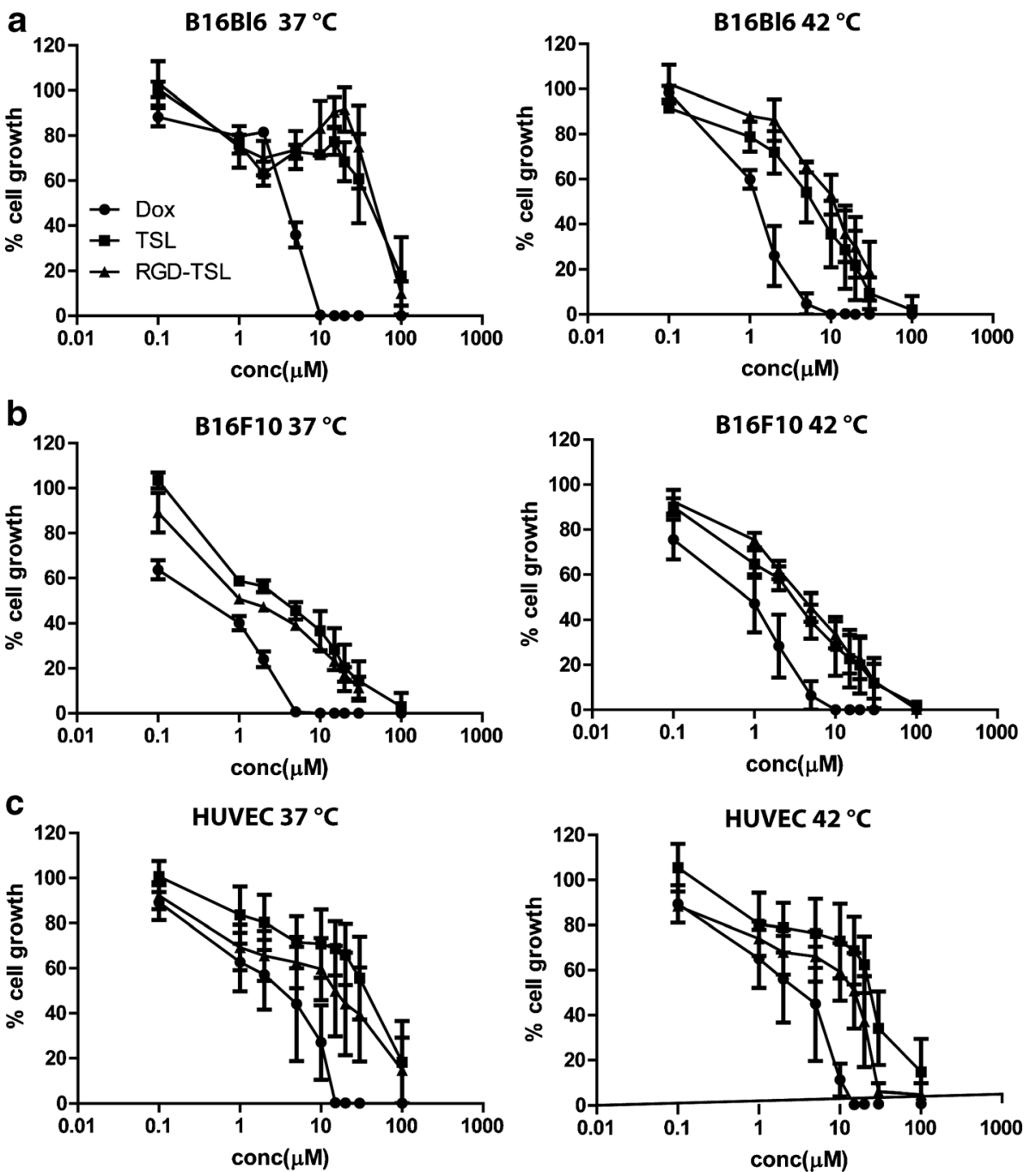

as it was higher for Dox from RGD-TSL than TSL (11.3 respectively v/s 8.3\% ID/g at NT; and $11 \mathrm{v} / \mathrm{s} \mathrm{6 \%} \mathrm{ID/g} \mathrm{at}$ HT). Similar high Dox accumulation in the kidney was observed from both formulations. Dox accumulated in the liver was similar for RGD-TSL and TSL under NT (3.9\% ID/g respectively v/s 2.7\% $\mathrm{ID} / \mathrm{g})$. The higher Dox uptake in spleen and liver from RGD-TSL is due to most probably opsonization of RGD-TSL by proteins in these organs. There was a minimal uptake of Dox from TSL and RGD-TSL in the heart, lungs and muscle upon NT and HT. No Dox was

Table I *IC 50 Values in $\mu$ M Dox of B 16BI6 Murine Melanoma, B I6FIO Murine Melanoma and Endothelial Cell (HUVEC) Treated with Free Dox or Dox Formulated in TSL or RGD-TSL for I h at $37^{\circ} \mathrm{C}$. After removal of unbound liposomes, cells were subjected to $\mathrm{HT}$ at $42^{\circ} \mathrm{C}$ for another I $\mathrm{h}$ (in blue) or NT (in black) as a control

\begin{tabular}{|l|c|c|c|}
\hline \multicolumn{4}{|c|}{ IC50 $(\mu \mathrm{M})$} \\
\hline Treatment & B16BL6 & B16F10 & HUVEC \\
\hline Dox & $3.8 \pm 0.3$ & $1.1 \pm 0.2$ & $5.7 \pm 2.6$ \\
TSL & $58.8 \pm 28$ & $8.6 \pm 5.5$ & $53.9 \pm 23.9$ \\
RGD-TSL & $44.4 \pm 8.9$ & $2.6 \pm 1.1$ & $51.0 \pm 26.2$ \\
\hline Dox & $1.5 \pm 0.3$ & $1.4 \pm 0.5$ & $4.9 \pm 1.9$ \\
TSL & $9.9 \pm 5.7$ & $6.2 \pm 3.1$ & $32.2 \pm 8.5$ \\
RGD-TSL & $12.6 \pm 4.2$ & $5.0 \pm 1.2$ & $16.9 \pm 4.8$ \\
\hline
\end{tabular}


Fig. 6 (a). Binding of DiD-labeled RGD-TSL (purple) to tumor vasculature (green) of $\mathrm{B} 16 \mathrm{Bl} 6$ window chamber bearing mice. Binding of liposomes to tumor endothelial cells started 20 min after injection and was followed in time up to $24 \mathrm{~h}$. Representative images from intravital microscopy were selected. Scale bar applies to all images, $50 \mu \mathrm{m}$. (b). RGD-TSL and TSL appearance (DiD, in purple) in tumor vasculature (green) during $5 \mathrm{~h}$ at NT in B $16 \mathrm{Bl} 16$ window bearing mice (Fig B left panels) and upon subsequent $\mathrm{HT}$ at $42^{\circ} \mathrm{C}$ for I $\mathrm{h}$ (Fig. 5b right panels). DiD-labelled RGD-TSL or TSL were injected i.v, after which they were allowed to circulate in blood stream at NT for $5 \mathrm{~h}$ in order to allow binding of RGD-TSL to angiogenic endothelial cells. Thereafter, $\mathrm{HT}$ at $42^{\circ} \mathrm{C}$ for I h was applied to promote extravasation of RGD-TSL and TSL. Scale bar applies to all images $50 \mu \mathrm{m}$. (c). In vivo quantification of DiD liposomal fluorescence before and during I h of $\mathrm{HT}$, presented as integrated density (IntDen) in time, see Materials and methods for details.
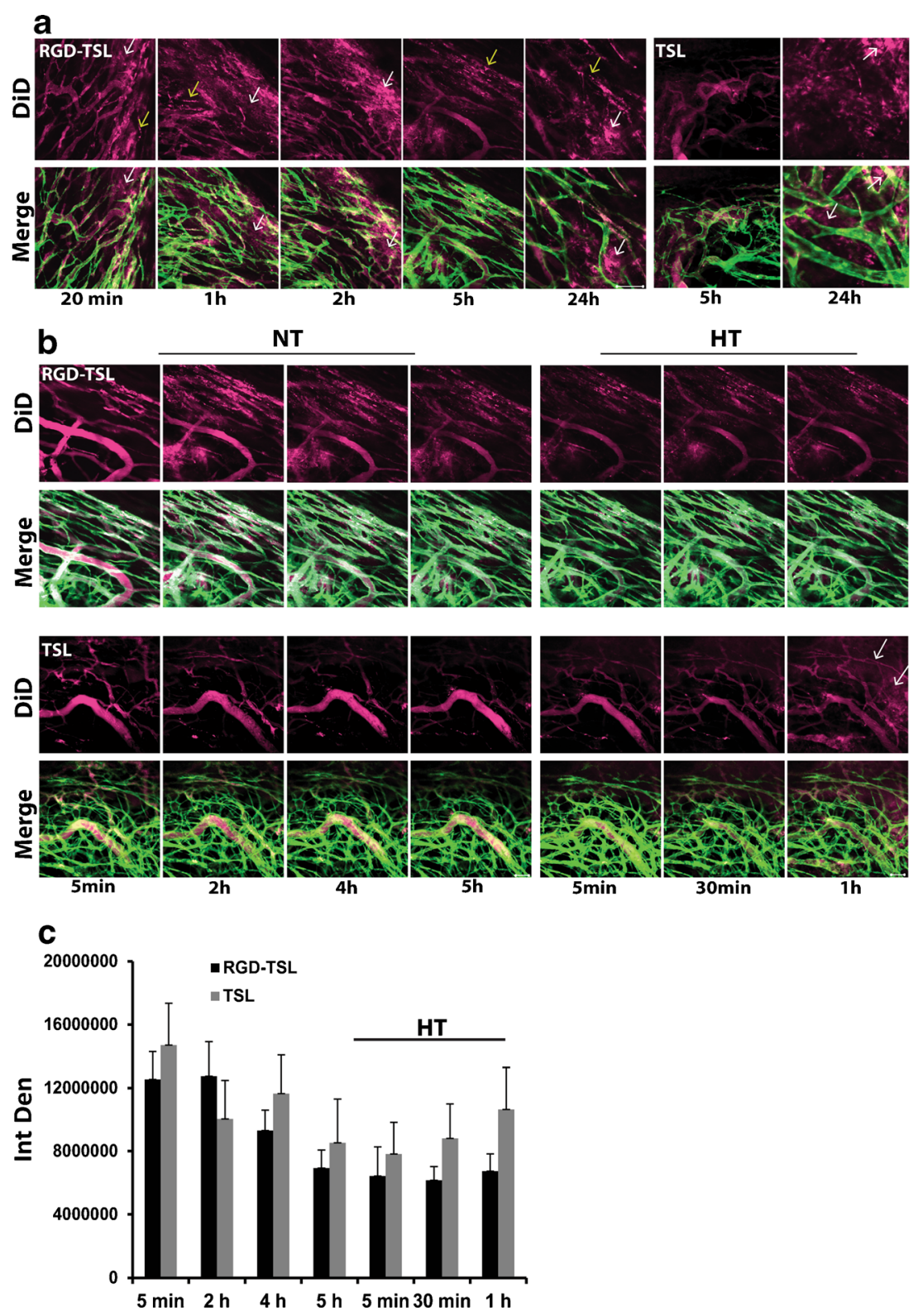

detected in the brain from neither of the formulations. At NT, the tumor uptake of Dox was similar for both formulations. Application of initial HT for $1 \mathrm{~h}$ at $41^{\circ} \mathrm{C}$ was able to cause 3.7 fold increase of Dox delivery to the tumor from RGDTSL $(1.6 \mathrm{v} / \mathrm{s} 6 \% \mathrm{ID} / \mathrm{g})$ and 2.3 fold increased Dox amount to the tumor from TSL $(1.7 \mathrm{v} / \mathrm{s} 4 \% \mathrm{ID} / \mathrm{g})$. The amount of Dox delivered to the tumor upon initial HT conditions from RGD-TSL was not significantly different from Dox delivered from TSL ( $p$-value 0.1 ).

\section{DISCUSSION}

Nanoparticles, such as liposomes have been successfully designed and used in treatment of various types of cancer (30).
Although modifications to these nanocarriers contributed to decreased drug-related side effects, their high stability (31-33) and limited tumor localization (34) prevent the desired increase in therapeutic outcome $(4,7)$. Forcing encapsulated drug to leave the liposome, as is achieved with TSL exposed to hyperthermia, leads to an enhanced drug release locally in the tumor (35-37). Also, application of an external trigger such as HT, can promote liposome extravasation from tumor vasculature and increase their accumulation locally in the tumor area (18-20, 38). When combined, this interstitial release approach relies primarily on HT-augmented liposome extravasation followed by heat-triggered drug release (39). More directly, improved drug accumulation is observed with the intravascular release approach, for instance with lysolipidthermosensitive liposomes (40). Next to the use of an external 


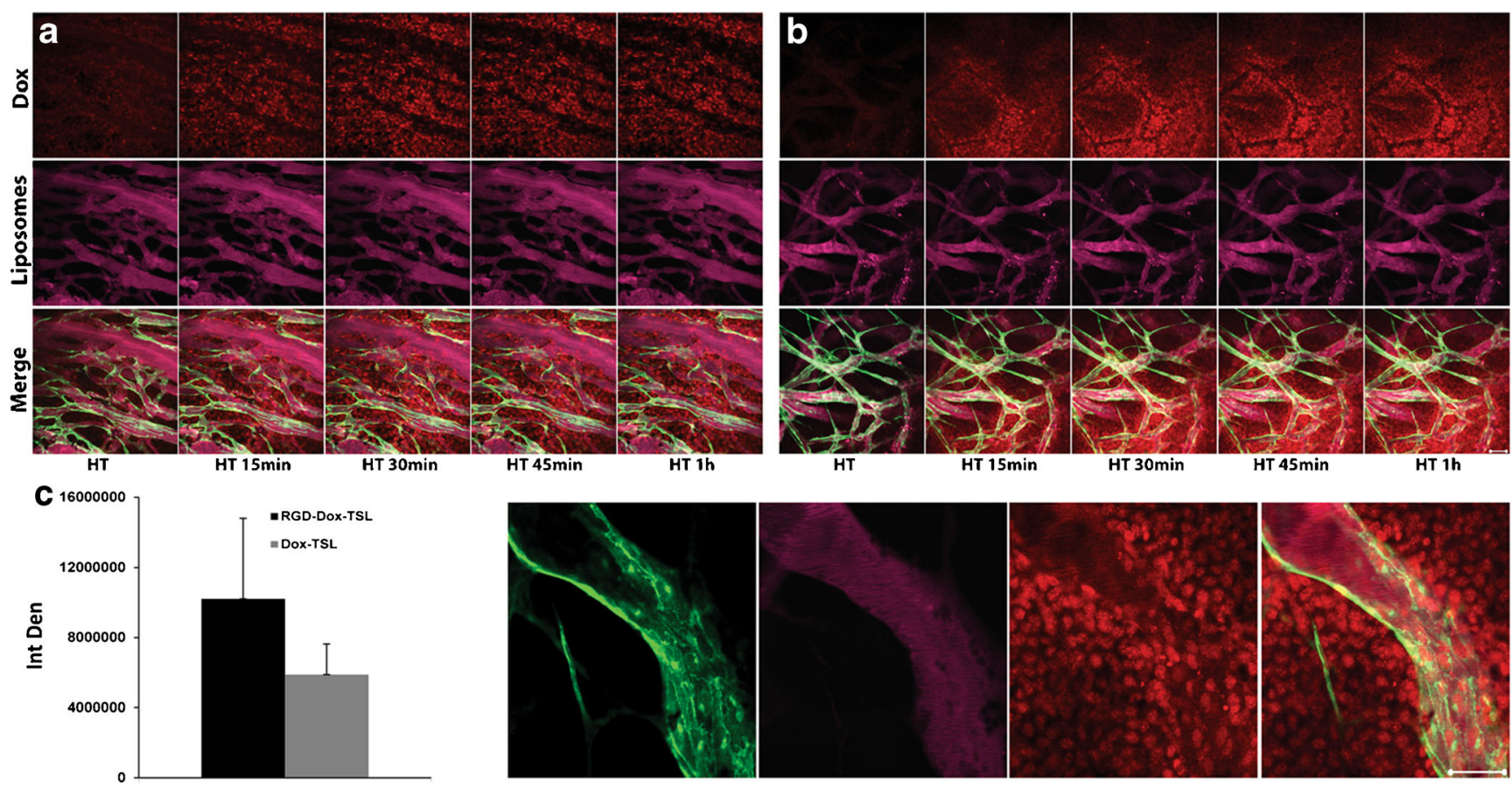

Fig. 7 Dox release upon HT treatment from TSL (a) and RGD-TSL (b) in BI6Bl6 window chamber bearing mice. Mice were injected with 5 mg/kg Dox in DiD-labelled (purple) TSL or RGD-TSL. After 5 h of liposome circulation, a temperature of $42^{\circ} \mathrm{C}$ for I h was applied to trigger Dox release. Representative images were taken from the beginning of the HT treatment up to I h. (c). In vivo quantification of Dox released from RGD-TSL or TSL I h after HT treatment, presented as integrated density (IntDen), see materials and methods. (d). Dox uptake in endothelial cells (green) and tumor cells from RGD-TSL after I h of HT treatment. Scale bar applies for all images, $50 \mu \mathrm{m}$.

trigger for controlling drug release, decorating liposomes with targeting ligands specific for the tumor cells or vasculature can also increase the liposomal drug efficacy. We have recently developed cationic thermosensitive liposomes, a nanoparticle
Fig. 8 Pharmacokinetics $(\mathbf{a}$ and $\mathbf{b})$ and biodistribution (c and $\mathbf{d}$ ) of Dox-TSL and Dox-RGD-TSL in B I6BL6 tumor bearing mice upon NT or initial HT conditions. A,C. At NT condition, mice were injected with $3 \mathrm{mg} / \mathrm{kg}$ Dox and blood sampling was performed at the indicated time points and organs collected $24 \mathrm{~h}$ after liposomes injection. At HTcondition (b and d), tumors in mice were preheated for I h at $41^{\circ} \mathrm{C}$ and cooled down for I 5 min, in order to allow for liposome extravasation. Then, liposomes were injected at $3 \mathrm{mg} / \mathrm{kg}$ Dox and blood samples were collected up to $24 \mathrm{~h}$, after which the organs were removed. The Dox concentration in the blood and organs was analyzed by HPLC. a

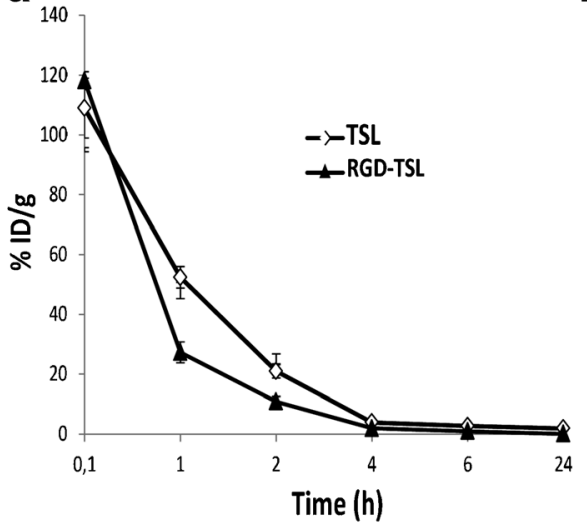

C

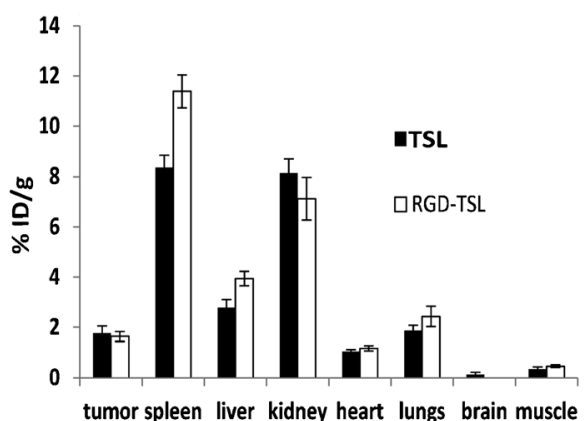

b

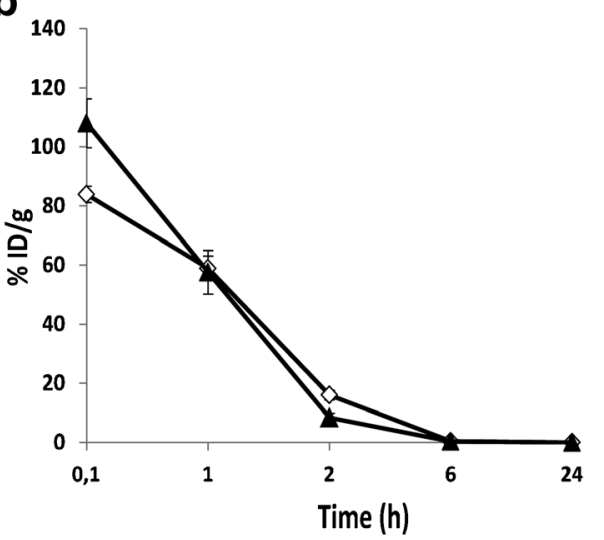

d

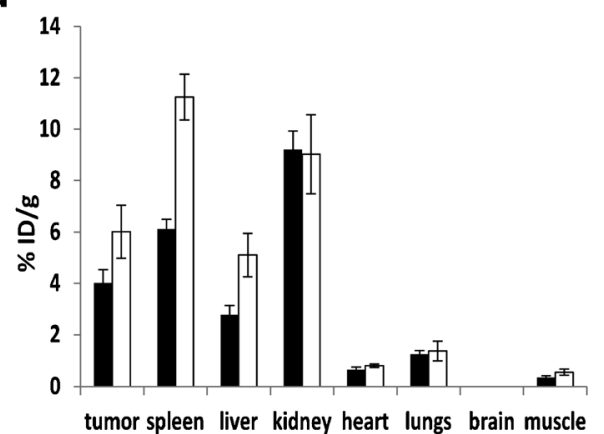


combining targeting and triggered release properties in one carrier $(41,42)$ and redesigned it in ordered to achieve a pharmaceutically stable formulation. In the present study, we report on the development of TSL decorated with another targeting ligand, $\mathrm{RGD}$ (RGDf[N-Met] $\mathrm{C}$, which is specific for integrins overexpressed on both tumor vasculature and tumor cells.

Engrafting of TSL with cRGD did not cause significant changes in the pharmaceutical properties of the formulation. Dox-TSL and Dox-RGD-TSL were similar in size, pdI, Dox encapsulation and Dox release kinetics. This is in accordance with Al-Ahmady et al. using monoclonal antibody-targeted thermosensitive liposomes showing that traditional thermosensitive liposomes maintain their physicochemical and thermal properties when conjugated to the monoclonal antibody (43). Both formulations showed to be stable at temperatures up to $38^{\circ} \mathrm{C}$, slightly released Dox at $39^{\circ} \mathrm{C}$ and at $42^{\circ} \mathrm{C}$ released $>90 \%$ of the encapsulated Dox in $1 \mathrm{~h}$,characteristics favorable for use in clinical settings. In accordance with Kim et al. (44) and Al-Ahmady et al. (43) there was a preferential uptake of RGD-TSL by both melanoma and endothelial cells, which was confirmed by FACS analysis and confocal microscopy (Fig. 3a and b). The specificity of RGD-TSL for the tested cell lines contributed to an increased Dox delivery to all the cell lines at both NT and HT conditions (Fig. 3c and d). After $1 \mathrm{~h}$ of incubation at NT with either TSL or RGD-TSL, there was an increased Dox uptake by all the cell lines from RGD-TSL. HT additionally triggered the drug release and uptake from TSL and RGD-TSL, which was higher for RGD-TSL than TSL. In accordance with AlAhmady et al. (43), the longer incubation period of $3 \mathrm{~h}$ at $37^{\circ} \mathrm{C}$ led to an increased Dox uptake in the cell lines and was higher again for RGD-TSL. However, the subsequent HT trigger did not change the drug uptake in the melanoma cell lines, which is most likely due to the fact that in the $3 \mathrm{~h}$ period the cells are able to degrade the liposomes themselves preventing an additional release upon HT. Only an increase in drug uptake upon HT after $3 \mathrm{~h}$ of incubation was observed with HUVECs, which might be due to the fact that these cells take longer time to entrap liposomes in acidic compartments in the cytosol (Fig. 4a). In contrast, B16Bl6 and B16F10 were able to process endocytosed RGD-TSL in a faster manner.

Using confocal microscopy, we demonstrated that HT was able to trigger drug release and uptake in vitro in melanoma and endothelial cells. After $3 \mathrm{~h}$ of incubation of the cells at $37^{\circ} \mathrm{C}$ with Dox-RGD-TSL, there was a premature drug release and uptake most likely due to cellular processing of the drug at this time point. However, HT additionally increased Dox delivery in all the cell lines and was mostly nuclear for melanoma cells and both nuclear and cytoplasmic for HUVEC (Fig. 4b and c), which is in accordance with Kim et al. (44). There was no difference in cytotoxicity of Dox-TSL and Dox-RGD-TSL to any of the cell lines at NT conditions.
A HT trigger could not further increase the cytotoxicity of Dox-RGD-TSL in B16F10 and HUVEC but only in B16Bl6. This is likely due to the nature of the assay in which cytotoxicity is measured $72 \mathrm{~h}$ after nanoparticle incubation and heat treatment. During the remaining $72 \mathrm{~h}$ also non-heat triggered RGD-TSL will release their Dox contents intracellularly due to nanoparticle processing, causing cellular cytotoxicity.

The $5 \mathrm{~h}$ targeting phase did not show any premature Dox release from neither RGD-TSL or TSL (data not shown), which is in accordance with other targeted TSL (42). During this phase, RGD-TSL bound to tumor endothelial cells already 20 min after liposome injection and were observed bound up to $24 \mathrm{~h}$. In contrast, TSL did not bind to tumor vasculature and were mostly extravasated $24 \mathrm{~h}$ after injection (Fig. 6a), which confirmed the targeting properties of RGD-TSL. Liposomes were cleared from circulation gradually in $5 \mathrm{~h}$, shown by intravital microscopy and image quantification. The application of HT could increase TSL extravasation starting at 30 min of HT and increasing up to $1 \mathrm{~h}$, which is in accordance with $\mathrm{Li}$ et al. (20) and Dicheva et al. (42) (Fig. 6b and c).

$\mathrm{HT}$ at $42^{\circ} \mathrm{C}$ could trigger a massive Dox release from both RGD-TSL and TSL. Release started already 5 min after heat trigger and increased up to $1 \mathrm{~h}$ (Fig. 7a). Image quantification from numerous positions in the tumor in several mice demonstrated that due to the RGD-TSL specificity for the tumor, these liposomes delivered 1.7 fold higher amount of doxorubicin than TSL (Fig. 7c). However, this difference was not statistically significant. Additionally, hyperthermia triggered release of Dox and Dox was subsequently taken up by both and angiogenic endothelial cells, which proves the dual targeting approach (Fig. 7d).

The pharmacokinetic behavior of Dox-TSL and Dox-RGDTSL was investigated with or without initial HT. Initial HT was used to increase liposome extravasation. Dox from RGD-TSL was cleared faster from circulation than Dox from TSL under NT. This observation might show that targeting influenced Dox clearance. However, upon HT conditions, Dox clearance from circulation from the two formulations was similar.

Biodistribution studies showed that the highest uptake of Dox-TSL and Dox-RGD-TSL was in the spleen and the kidneys followed by the liver (Fig. 8c and d). The high spleen and liver uptake are due to the fact that these organs are part of the mononuclear phagocyte system (MPS), which is responsible for filtering out of liposomes from the blood circulation (45). There was no explanation why kidneys had an increased Dox uptake at both NT and HT conditions. As expected, there was a little Dox uptake from the two formulations under NT and HT in heart and lungs and no uptake in brain and the leg muscle close to the heated tumor. The absence of Dox in the leg muscle shows that the heating was restricted only to the tumor. There was not a difference in tumor uptake of Dox under NT by any of the formulations showing that targeting do not contribute to increased drug uptake at this conditions. However, when initial 
HT for $1 \mathrm{~h}$ at $41^{\circ} \mathrm{C}$ was applied, there was an increased Dox uptake in the tumor from both formulations, which is likely due to increased extravasation of liposomes upon HT and therefore their higher accumulation at the tumor site.

Future experiments will focus on improving the HT treatment protocols and will address the efficacy of our dual targeted and triggered drug delivery approach using cRGD thermosensitive liposomes.

\section{CONCLUSION}

RGD-TSL encapsulating Dox were successfully developed with both targeting and triggered properties. They demonstrated specificity to tumor and endothelial cells as compared to non-targeted TSL. RGD-TSL were taken up by acidic compartments in cytosol and intracellularly released Dox upon HT. In viwo, RGD-TSL bound to angiogenic endothelial cells and massively released Dox when HT was applied. Biodistribution studies showed that initial HT treatment increases Dox delivery to the tumor from both formulations. Further studies will address the efficacy of our dual targeted and triggered Dox delivery approach using RGD-TSL.

\section{ACKNOWLEDGMENTS AND DISCLOSURES}

We thank Dr. Marcel Verheijen and Monja Kaiser, Philips Research Eindhoven, NL for TEM cryo imaging, Sandra van den Bosch and Prof. Holger Grull, Philips Research Eindhoven, NL for assistance in pharmacokinetics and biodistribution studies, Thomas Soulie and Debby Schipper, Erasmus MC, Laboratory Experimental Surgical Oncology, Rotterdam for support in some in vitro experiments, and Dr. Peter Burgers, Erasmus MC, Rotterdam for MALDI analysis.

Open Access This article is distributed under the terms of the Creative Commons Attribution 4.0 International License (http://creativecommons.org/licenses/by/4.0/), which permits unrestricted use, distribution, and reproduction in any medium, provided you give appropriate credit to the original author(s) and the source, provide a link to the Creative Commons license, and indicate if changes were made.

\section{REFERENCES}

1. Allen TM, Cullis PR. Drug delivery systems: entering the mainstream. Science. 2004;303(5665):1818-22.

2. Maeda H, Wu J, Sawa T, Matsumura Y, Hori K. Tumor vascular permeability and the EPR effect in macromolecular therapeutics: a review. J Control Release. 2000;65(1-2):271-84.
3. Prabhakar U, Maeda H, Jain RK, Sevick-Muraca EM, Zamboni W, Farokhzad OC, et al. Challenges and key considerations of the enhanced permeability and retention effect for nanomedicine drug delivery in oncology. Cancer Res. 2013;73(8):2412-7.

4. Judson I, Radford JA, Harris M, BlayJY, van Hoesel Q, le Cesne A, et al. Randomised phase II trial of pegylated liposomal doxorubicin (DOXIL/CAELYX) versus doxorubicin in the treatment of advanced or metastatic soft tissue sarcoma: a study by the EORTC Soft Tissue and Bone Sarcoma Group. Eur J Cancer. 2001;37(7): $870-7$.

5. Northfelt DW, Dezube BJ, Thommes JA, Miller BJ, Fischl MA, Friedman-Kien A, et al. Pegylated-liposomal doxorubicin versus doxorubicin, bleomycin, and vincristine in the treatment of AIDS-related Kaposi's sarcoma: results of a randomized phase III clinical trial. J Clin Oncol. 1998;16(7):2445-51.

6. O'Brien Jr JM, Needham DM. Towards a better understanding of body mass index and patient outcomes. Anesth Analg. 201 1;112(1): $8-10$.

7. O'Brien ME, Wigler N, Inbar M, Rosso R, Grischke E, Santoro A, et al. Reduced cardiotoxicity and comparable efficacy in a phase III trial of pegylated liposomal doxorubicin HCl (CAELYX/Doxil) versus conventional doxorubicin for first-line treatment of metastatic breast cancer. Ann Oncol. 2004;15(3):440-9.

8. Dvorak HF, Nagy JA, Dvorak JT, Dvorak AM. Identification and characterization of the blood vessels of solid tumors that are leaky to circulating macromolecules. Am J Pathol. 1988;133(1):95-109.

9. Matter A. Tumor angiogenesis as a therapeutic target. Drug Discov Today. 2001;6(19):1005-24.

10. Campbell RB, Ying B, Kuesters GM, Hemphill R. Fighting cancer: from the bench to bedside using second generation cationic liposomal therapeutics. J Pharm Sci. 2009;98(2):411-29.

11. Jain RK. Vascular and interstitial barriers to delivery of therapeutic agents in tumors. Cancer Metastasis Rev. 1990;9(3): 253-66.

12. Gottschalk KE, Kessler H. The structures of integrins and integrinligand complexes: implications for drug design and signal transduction. Angew Chem Int Ed Engl. 2002;41(20):3767-74.

13. Mas-Moruno C, Rechenmacher F, Kessler H. Cilengitide: the first anti-angiogenic small molecule drug candidate design, synthesis and clinical evaluation. Anticancer Agents Med Chem. 2010;10(10):753-68.

14. Conforti G, Dominguez-Jimenez C, Zanetti A, Gimbrone Jr MA, Cremona O, Marchisio PC, et al. Human endothelial cells express integrin receptors on the luminal aspect of their membrane. Blood. 1992;80(2):437-46.

15. Seftor RE, Seftor EA, Hendrix MJ. Molecular role(s) for integrins in human melanoma invasion. Cancer Metastasis Rev. 1999;18(3): 359-75.

16. Ruoslahti E. RGD and other recognition sequences for integrins. Annu Rev Cell Dev Biol. 1996;12:697-715.

17. Dreher MR, Liu W, Michelich CR, Dewhirst MW, Chilkoti A. Thermal cycling enhances the accumulation of a temperaturesensitive biopolymer in solid tumors. Cancer Res. 2007;67(9): 4418-24.

18. Kong G, Braun RD, Dewhirst MW. Hyperthermia enables tumorspecific nanoparticle delivery: effect of particle size. Cancer Res. 2000;60(16):4440-5.

19. Kong G, Braun RD, Dewhirst MW. Characterization of the effect of hyperthermia on nanoparticle extravasation from tumor vasculature. Cancer Res. 2001;61(7):3027-32.

20. Li L, ten Hagen TL, Bolkestein M, Gasselhuber A, Yatvin J, van Rhoon GC, et al. Improved intratumoral nanoparticle extravasation and penetration by mild hyperthermia. J Control Release. 2013;167(2):130-7.

21. Li L, Ten Hagen TL, Hossann M, Suss R, van Rhoon GC, Eggermont AM, et al. Mild hyperthermia triggered doxorubicin 
release from optimized stealth thermosensitive liposomes improves intratumoral drug delivery and efficacy. J Control Release. 2013;168(2):142-50

22. Dewhirst MW, Landon CD, Hofmann CL, Stauffer PR. Novel approaches to treatment of hepatocellular carcinoma and hepatic metastases using thermal ablation and thermosensitive liposomes. Surg Oncol Clin N Am. 2013;22(3):545-61.

23. Grull H, Langereis S. Hyperthermia-triggered drug delivery from temperature-sensitive liposomes using MRI-guided high intensity focused ultrasound. J Control Release. 2013;161(2):317-27.

24. Sawant RR, Torchilin VP. Challenges in development of targeted liposomal therapeutics. AAPS J. 2012;14(2):303-15.

25. Dicheva BM, Koning GA. Targeted thermosensitive liposomes: an attractive novel approach for increased drug delivery to solid tumors. Expert Opin Drug Deliv. 2014;11(1):83-100.

26. Amin M, Badiee A, Jaafari MR. Improvement of pharmacokinetic and antitumor activity of PEGylated liposomal doxorubicin by targeting with $\mathrm{N}$-methylated cyclic RGD peptide in mice bearing C-26 colon carcinomas. Int J Pharm. 2013;458(2):324-33.

27. Rouser G, Fkeischer S, Yamamoto A. Two dimensional then layer chromatographic separation of polar lipids and determination of phospholipids by phosphorus analysis of spots. Lipids. 1970;5(5): 494-6.

28. Hossann M, Wiggenhorn M, Schwerdt A, Wachholz K, Teichert $\mathrm{N}$, Eibl $\mathrm{H}$, et al. In vitro stability and content release properties of phosphatidylglyceroglycerol containing thermosensitive liposomes. Biochim Biophys Acta. 2007;1768(10):2491-9.

29. Haran G, Cohen R, Bar LK, Barenholz Y. Transmembrane ammonium sulfate gradients in liposomes produce efficient and stable entrapment of amphipathic weak bases. Biochim Biophys Acta. 1993;1151(2):201-15.

30. Allen TM, Gullis PR. Liposomal drug delivery systems: from concept to clinical applications. Adv Drug Deliv Rev. 2013;65(1):3648 .

31. Laginha KM, Verwoert S, Charrois GJ, Allen TM. Determination of doxorubicin levels in whole tumor and tumor nuclei in murine breast cancer tumors. Clin Cancer Res. 2005;11(19 Pt 1):6944-9.

32. Seynhaeve AL, Dicheva BM, Hoving S, Koning GA, Ten Hagen TL. Intact Doxil is taken up intracellularly and released doxorubicin sequesters in the lysosome: evaluated by in vitro/in viwo live cell imaging. J Control Release. 2013;172(1):330-40.

33. Seynhaeve AL, Hoving S, Schipper D, Vermeulen CE, de WielAmbagtsheer G, van Tiel ST, et al. Tumor necrosis factor alpha mediates homogeneous distribution of liposomes in murine melanoma that contributes to a better tumor response. Cancer Res. 2007;67(19):9455-62.
34. Harrington KJ, Mohammadtaghi S, Uster PS, Glass D, Peters AM, Vile RG, et al. Effective targeting of solid tumors in patients with locally advanced cancers by radiolabeled pegylated liposomes. Clin Cancer Res. 2001;7(2):243-54.

35. Abu Lila AS, Doi Y, Nakamura K, Ishida T, Kiwada H. Sequential administration with oxaliplatin-containing PEG-coated cationic liposomes promotes a significant delivery of subsequent dose into murine solid tumor. J Control Release. 2010;142(2):167-73.

36. Needham D, Anyarambhatla G, Kong G, Dewhirst MW. A new temperature-sensitive liposome for use with mild hyperthermia: characterization and testing in a human tumor xenograft model. Cancer Res. 2000;60(5):1197-201.

37. Yatvin MB, Weinstein JN, Dennis WH, Blumenthal R. Design of liposomes for enhanced local release of drugs by hyperthermia. Science. 1978;202(4374):1290-3.

38. Huang SK, Stauffer PR, Hong K, Guo JW, Phillips TL, Huang A, et al. Liposomes and hyperthermia in mice: increased tumor uptake and therapeutic efficacy of doxorubicin in sterically stabilized liposomes. Cancer Res. 1994;54(8):2186-91.

39. Koning GA, Eggermont AM, Lindner LH, ten Hagen TL. Hyperthermia and thermosensitive liposomes for improved delivery of chemotherapeutic drugs to solid tumors. Pharm Res. 2010;27(8):1750-4.

40. Manzoor AA, Lindner LH, Landon CD, Park JY, Simnick AJ, Dreher MR, et al. Overcoming limitations in nanoparticle drug delivery: triggered, intravascular release to improve drug penetration into tumors. Cancer Res. 2012;72(21):5566-75.

41. Dicheva BM, ten Hagen TL, Li L, Schipper D, Seynhaeve AL, van Rhoon GC, et al. Cationic thermosensitive liposomes: a novel dual targeted heat-triggered drug delivery approach for endothelial and tumor cells. Nano Lett. 2013;13(6):2324-31.

42. Dicheva BM, Ten Hagen TL, Schipper D, Seynhaeve AL, van Rhoon GC, Eggermont AM, et al. Targeted and heat-triggered doxorubicin delivery to tumors by dual targeted cationic thermosensitive liposomes. J Control Release 2014; 10(195):37-48.

43. Al-Ahmady ZS, Chaloin O, Kostarelos K. Monoclonal antibodytargeted, temperature-sensitive liposomes: in viwo tumor chemotherapeutics in combination with mild hyperthermia. J Control Release. 2014;196:332-43.

44. Kim MS, Lee DW, Park K, Park SJ, Choi EJ, Park ES, et al. Temperature-triggered tumor-specific delivery of anticancer agents by cRGD-conjugated thermosensitive liposomes. Colloids Surf B: Biointerfaces. 2014;1 16:17-25.

45. Drummond DC, Noble CO, Hayes ME, Park JW, Kirpotin DB. Pharmacokinetics and in vivo drug release rates in liposomal nanocarrier development. J Pharm Sci. 2008;97(11):4696-740. 